This is a self-archived - parallel published version of this article in the publication archive of the University of Vaasa. It might differ from the original.

\title{
Does Option-Implied Cross-Sectional Return Dispersion Forecast Realized Cross-Sectional Return Dispersion? Evidence From the G10 Currencies
}

Author(s): Grobys, Klaus; Heinonen, Jari-Pekka

Title: Does Option-Implied Cross-Sectional Return Dispersion Forecast Realized Cross-Sectional Return Dispersion? Evidence From the G10 Currencies

Year: $\quad 2016$

Version: Accepted manuscript

Copyright (C) 2016 Wiley. This is the pre-peer reviewed version of the following article: Grobys, K. \& Heinonen, J.-P. (2016). Does Option-Implied Cross-Sectional Return Dispersion Forecast Realized Cross-Sectional Return Dispersion? Evidence From the G1o Currencies. Journal of Futures Markets 37(1), 3-22, which has been published in final form at https://doi.org/10.1002/fut.21798. This article may be used for noncommercial purposes in accordance with Wiley Terms and Conditions for Use of Self-Archived Versions.

\section{Please cite the original version:}

Grobys, K. \& Heinonen, J.-P. (2016). Does Option-Implied CrossSectional Return Dispersion Forecast Realized Cross-Sectional Return Dispersion? Evidence From the G10 Currencies. Journal of Futures Markets 37(1), 3-22. https://doi.org/10.1002/fut.21798 


\title{
Does Option-Implied Cross-Sectional Return Dispersion Forecast Realized Cross-Sectional Return Dispersion? Evidence From the G10 Currencies
}

\author{
Klaus Grobys* and Jari-Pekka Heinonen
}

\begin{abstract}
This study employs option-price data to back out the implied cross-sectional return variance in the G10 currencies. It investigates the relation of implied cross-sectional return dispersion in the currency market and subsequent realized cross-sectional return dispersion. We find that implied cross-sectional return variance, based on option-price data with 1- and 3-month maturity, outperforms past cross-sectional return variance in forecasting future cross-sectional return variance. (C) 2016 Wiley Periodicals, Inc. Jrl Fut Mark
\end{abstract}

\section{INTRODUCTION}

A broad strand of literature explores the extent to which the implied information in the option market can predict future volatility. Christensen and Prabhala (1998) argue that the volatility implied in an option's price is widely regarded as the option market's forecast of future return volatility over the remaining life of the relevant option. Many studies have demonstrated that option-implied volatility is an accurate predictor of subsequently realized volatility. ${ }^{1}$ In recent research Nikolaou and Sarno (2006) focus on the options markets and substitute the standard forward contract with an option equivalent contract to test option-based unbiasedness. This approach allows the above mentioned research to compare the two derivatives markets - the forward and the options market -in terms of the statistical

\footnotetext{
Klaus Grobys and Jari-Pekka Heinonen are at the Department of Accounting and Finance, University of Vaasa, Wolffintie 34, 65200 Vaasa, Finland. We received valuable comments from seminar participants at a research seminar in accounting and finance at the University of Vaasa and 2015. In particular, we want to thank Jukka Sihvonen for useful comments. We also received valuable comments from participants at the 2015 winter workshop organized by the Graduate School of Finance in Helsinki. In particular, we are grateful to Joonas Hamalainen for providing a very helpful discussion on our paper. We are also very grateful for the valuable and helpful comments received from an anonymous reviewer.
}

JEL Classification: G12, G14

${ }^{*}$ Correspondence author, Department of Accounting and Finance, University of Vaasa, Wolffintie 34, 65200 Vaasa, Finland. Tel: +358466110151, e-mail: klaus.grobys@uwasa.fi; grobys.finance@gmail.com

Received February 2016; Accepted June 2016

${ }^{1}$ Classic contributions include Day and Lewis (1992), Canina and Figlewski (1993), Lamoureux and Lastrapes (1993), Christensen and Prabhala (1998), Fleming (1998), and Blair, Poon, and Taylor (2001), Szakmarya, Orsb, Kimc, and Davidson (2003), Busch, Christensen, and Nielsen (2011), and Chang, Christoffersen, Jacobs, and Vainberg (2011). 
properties of the resulting contracts. That comparison in turn makes it possible to evaluate whether or not the bias puzzle recorded in the literature is forward specific or a problem of a more general nature. Della Corte, Sarno, and Tsiakas (2011) explore the relation between spot and forward implied volatility in foreign exchange by formulating and testing the forward volatility unbiasedness hypothesis that postulates that forward implied volatility conditional on today's information is an unbiased predictor of future spot implied volatility. The study makes use of implied volatilities for nine US dollar exchange rates quoted on over-thecounter (OTC) currency options. In a recent paper, Della Corte, Ramadorai, and Sarno (2016) use the currency volatility risk premium to implement a trading strategy long on currencies with relatively cheap volatility insurance and short on currencies with relatively expensive volatility insurance. Making use of the volatility risk premium requires estimating the expected future realized currency volatility derived from the currency options. Interestingly, those papers focus on option-implied volatility because there are apparently no articles exploring the predictive power of option-implied cross-sectional currency return dispersion. It is important to note that the concept of implied volatility and implied crosssectional return dispersion are very different (Maio, 2016). ${ }^{2}$

The purpose of this article is to investigate the information content of option-implied cross-sectional return dispersion in the foreign exchange $(\mathrm{FX})$ market for forecasting realized cross-sectional return dispersion. If option markets are efficient, implied cross-sectional return dispersion should be an unbiased predictor of future cross-sectional return dispersion, that is, implied cross-sectional return dispersion should integrate the information contained in all other variables in the market information set in explaining future cross-sectional return dispersion.

This study expresses the cross-sectional currency return dispersion in the G-10 currencies as a sum of the weighted differences of the variances of individual currencies and an equally weighted basket of USD/G-10-crosses. This form of expression allows the exploitation of information drawn from the option market to construct the forward-looking dispersion measure with implied variances and the currencies' full implied G-10 correlation structure. We collect the at-the-money (ATM) volatility data on four different maturities (1-, 3-, 6-, and 12month) of European OTC foreign exchange options, covering the full cross section of 45 G-10 cross-pairs and spanning the period October 2007-August 2015. Exploiting the full cross section of monthly implied variance observations and the holding triangular parity condition, we back out four (1-, 3-, 6-, and 12-month) monthly time series of full $(9 \times 9)$ implied correlation matrices. Owing to some inefficiencies in Bloomberg's volatility data on the most exotic of the 45 crosses, we adjusted the eigenvalues of the backed out matrices in a process detailed in Higham (2002) in order to obtain true correlation matrices. With the full expected (option-implied) correlation matrices in four tenors and their respective variances, we calculated the forward-looking measure of dispersion by constructing four time series of equally weighted G-10 basket variances in the spirit of Markowitz (1952) and distracting them from the weighted basket of individual variances. These 1-, 3-, 6-, and 12-month forwardlooking measures were labeled implied dispersions. They represent the option markets (tradable) view on the expected cross-sectional variance (hence the term dispersion) at four different future points in time. As a result, based on the option's maturity, we employed four implied cross-sectional currency return dispersion measures.

Although the works of Nikolaou and Sarno (2006), Della Corte et al. (2011), and Della Corte et al. (2016) are important precursors to this paper, our empirical setting is different and more general, and thus resembles that used in an earlier study by Christensen and Prabhala (1998). We employed four different series of implied cross-sectional return

\footnotetext{
${ }^{2}$ The volatility surfaces of the options not only provide information about implied volatility, but also on implied crosssectional return dispersion.
} 
dispersion for the G-10 currencies and regressed the realized return dispersion (RD) on the implied measures. The regression analyses we conducted also controlled for past-realized cross-sectional variance and made use of the instrument variable estimation technique. In an additional analysis, we employed a bootstrapping approach to check the robustness of our results.

Our paper contributes to the literature in some important ways. This is the first paper that investigates the information content of option-implied cross-sectional return variance in FX markets. If cross-sectional RD is a macroeconomic state variable, as argued by Chichernea, Holder, and Petkevich (2015) and Stivers and Sun (2010), it may be of interest not only to investors but also to policy makers, as it could offer an unbiased forecast of future states of the economy that could in turn guide effective political action over time. Whereas Chichernea et al. (2015) and Stivers and Sun (2010) focus on the equity market alone, our paper focuses exclusively on the currency market. This is an important extension of the previous literature because Menkhoff, Sarno, Schmeling, and Schrimpf (2012) emphasize that foreign exchange markets are more liquid than equity markets, and feature huge transaction volumes and low trading costs. More precisely, according to the Bank of International Settlement, the average daily turnover of the FX market measured in April 2013 amounted to USD 5.345 billion compared to USD 468 billion in the equity markets, which highlights the importance of the FX markets in terms of turnover. ${ }^{3}$ Moreover, we focus on the most liquid currencies, the so-called G10 currency space which comprises about $70 \%$ of the total traded volume. ${ }^{4}$

Furthermore, our paper contributes to the strand of literature exploring the predictive power of implied correlations using option-price data. Skintzi and Refenes (2005) use Dow Jones Industrial Average index options to back out an implied correlation index, which reflects the market view of the future level of the market portfolio diversification. As a standard procedure for equity markets, Skintzi and Refenes use equicorrelation matrices as a basis for their index. The method employs individual volatilities and weights, and gives every asset in an index the same correlation coefficient, so that the portfolio volatility matches the index option volatility. As a result, Skintzi and Refenes' proposed equicorrelation index is an average correlation in the index, and their findings provide evidence that the implied correlation index fluctuates substantially over time and displays strong dynamic dependence. Moreover, the same research identifies a systematic tendency for the implied correlation index to increase when the market index returns decrease and/or the market volatility increases, which indicates there is limited diversification when it is needed most. Although the implied correlation index is found to be a biased forecast of realized correlation, it does exhibit a high explanatory power and is orthogonal to the information set compared to a historical forecast. Interestingly, there is apparently no study that measures the magnitude of the whole diversification effect by explicitly calculating the covariance term. ${ }^{5}$ The current research fills this gap in the literature, and is the first to make use of both measures in one model simultaneously, and hence, it extends the relevant strand of literature. Specifically, our implied dispersion measure resembles the method applied by Skintzi and Refenes (2005). However, first, instead of employing the equicorrelation coefficient, as proposed in Skintzi and Refenes (2005), we apply the true implied correlation structure of the G-10 basket. Second, we measure the magnitude of the whole diversification effect, the covariance term, rather than calculating the average correlation coefficient in the basket.

\footnotetext{
${ }^{3}$ Triennial Central Bank Survey Foreign exchange turnover in April 2013: preliminary global results Monetary and Economic Department September 2013, page 10. See also http://www.world-exchanges.org/insight/reports/globalequity-trading-volumes-rise-36-1st-half-2015.

${ }^{4}$ See Tables 1, 5, and 6 in Triennial Central Bank Survey Foreign exchange turnover in April 2013: preliminary global results Monetary and Economic Department September 2013.
} 
Our empirical findings indicate that the implied cross-sectional variances based on 1- and 3-month maturities predict the realized cross-sectional variance. It is striking that employing the implied cross-sectional variance based on options with 1-month maturity generates forecasts that do not involve systematic errors because the intercept term in the regression model used for our empirical test is statistically not different from zero. Controlling for pastrealized cross-sectional variance does not change the results and shows that realized crosssectional variance has virtually no predictive power. In additional robustness checks, we made use of the instrument variable estimation technique, and a non-parametric approach to compound robust $t$-statistics. Both robustness checks confirmed our findings.

This paper is organized as follows. The next section provides a literature review. The third section describes the data. The fourth section provides an overview of the theoretical model and the computation of the implied cross-sectional variances using the G-10 currencies. The fifth section describes the empirical methodology, and the final section presents the study's conclusions.

\section{LITERATURE REVIEW}

This section explains first the relevance of our research related to exploring the predictive power of an option-implied measure for cross-sectional RD from an asset pricing perspective, and second outlines the implications of being able to predict cross-sectional RD.

In recent research Chichernea et al. $(2015$, p. 147) point out that cross-sectional RD in the equity market caches information related to fundamental economic restructuring. "Specifically, RD is likely to capture the uncertainty associated with economic transitions and the flexibility of adaptability to fundamental economic restructuring [in line with Pastor and Veronesi (2009) and Demirer and Jategaonkar (2013)], rather than shocks related to the business cycle." The authors establish a robust link between cross-sectional RD and the accrual anomaly. In a recent paper, Grobys (2015) establishes a robust link between the asset growth anomaly and RD. In the same article, and following Chichernea et al. (2015), Grobys (2015) defines periods of high cross-sectional RD as states of economic stress, and periods of low return cross-sectional RD as good economic states. More specifically, states of the economy are identified as good or bad states when RD is above or below its median values, respectively. The findings indicate that when the economy is quiet, the spread between low and

\footnotetext{
${ }^{5}$ Other classic contributions exploring implied correlations are Bodurtha and Shen (1999), Siegel (1997), Campa and Chang (1998), Lopez and Walter (2000). Bodurtha and Shen (1999) use options data from the Philadelphia Stock Exchange. They find that both historical and implied correlations provide useful information in forecasting realized correlation. Siegel (1997) also uses the Philadelphia Stock Exchange data to examine the forecasting performance of implied correlation in the context of a cross currency hedging. Siegel (1997) finds that the hedges based on implied correlations perform significantly better in some cases and never significantly worse than the timeseries hedges. Furthermore, results indicate that the hedge ratios based on historical correlations provide no additional information beyond that already reflected in the hedge ratios based on implied correlations. Campa and Chang (1998) use data from the over-the-counter (OTC) market for FX options and find that implied correlation outperforms the other forecasts. In particular, they find that none of the time-series forecasts are consistently capable of providing additional information relative to the implied correlation forecasts. Lopez and Walter (2000), study the predictive content of implied correlations obtained from foreign exchange options for future realized correlations between exchange rates.

${ }^{6}$ The theoretical link between RD, macroeconomic states and stock returns has been established by models proposed by Gomes et al. (2003) and Zhang (2005). These models predict that RD can be a useful macroeconomic state variable caching information associated with aggregate investing conditions faced by firms. More precisely, periods with high RD indicate economic states with higher discount rates, which are not advantageous for investment or growth. Jiang (2010) demonstrates that RD is priced in the cross section and argues that it captures risk related to aggregate economic growth and fundamental economic restructuring.
} 
high investment firms is small and insignificant, whereas the spread is economically large and statistically significant in times of economic stress.

Grobys and Kolari (2015) demonstrate that a whole set of asset pricing anomalies in the US equity market can be explained by changes in the state of RD. ${ }^{7}$ Their results indicate that at least five of the twelve benchmark-adjusted long-short spreads of anomalies varied systematically with changes in the state of the economy and that eight of twelve anomalies exhibited at least marginally significant differences in average returns associated with long-short spreads.

Connolly and Stivers (2003) and Stivers and Sun (2010) find a link between RD and return momentum in equities. Stivers and Sun (2010, p.988) stress that "...RD may contain incremental information about the current state of the economy, beyond market-level return.” Their argument aligns with that of Chichernea et al. (2015) who also argue that RD is a macroeconomic state variable. Maio (2016) analyzes whether RD provides useful information about future (excess) stock returns, both at the aggregate and portfolio levels. His findings from (in-sample) single longhorizon regressions show that RD consistently predicts a reduction in both returns and excess returns for the stock index. Moreover, RD shows the best overall performance among different predictors in predicting both the market return and the equity premium.

Despite the volume of literature offering evidence that cross-sectional RD is an important macroeconomic state variable driving a whole set of asset pricing anomalies, it is surprising that no study has yet investigated whether the implied information in the option market can be used to predict future cross-sectional RD.

It is also notable that there is apparently no article investigating the relevance of crosssectional RD in a FX market setting, despite Menkhoff, Sarno, Schmeling, and Schrimpf (2012) showing that foreign exchange (FX) markets are more liquid than equity markets and feature considerable transaction volumes with relatively low transaction costs. Other important features of FX markets are that they are populated largely by sophisticated professional investors, and there are no natural short-selling constraints that prevent the shorting of past loser assets to implement zero-cost trading strategies. To the best of our knowledge, the only study that investigates asset pricing implications of cross-sectional RD in a currency market setting is that of Grobys, Heinonen and Kolari (2015). The study shows that changes in the state of RD are linked to the payoffs of the momentum strategy implemented in currency markets. Interestingly, the authors found that cross-sectional currency $\mathrm{RD}$ and cross-sectional global equity $\mathrm{RD}$ have a co-integration relationship, suggesting that the same global economic risk component is present in equity markets.

If cross-sectional RD is a macroeconomic state variable (Chichernea et al., 2015; Stivers and Sun, 2010), it may be of interest not only to investors but also policy makers, as it could offer an efficient forecast of future states of the economy that could in turn guide effective political action over time.

Exploration of the potential links between cross-sectional RD and cross-sectional asset pricing anomalies has attracted considerable attention in recent finance literature. However, our literature review reveals that there are a couple of important gaps in the literature: First, all research papers reviewed apart from one focused exclusively on equity market settings despite the relevance of the considerably larger and more liquid FX market. Second, crosssectional RD has been linked to many cross-sectional asset pricing anomalies, in both the equity and currency market, but there is no study available exploring whether or not it is possible to predict cross-sectional RD by using the information from the option market. The current research fills these gaps in the literature.

\footnotetext{
${ }^{7}$ Grobys and Kolari's (2015) model accounts for good and bad states of the economy that stochastically regimeswitch. Because cross-sectional RD exhibits high auto-correlation, the study employed an autoregressive two-state Markov-switching model that accounted for the latent state variable.
} 


\section{DATA}

The G-10 implied correlation structures used in the empirical analysis are extracted from monthly closing volatility quotes of 3-, 6-, and 12-month European vanilla OTC currency options for 45 different crosses. ${ }^{8}$ In the FX OTC option markets, the volatilities are quoted with respect to their Garman-Kohlhagen deltas instead of strikes. All the quoted volatility levels in all four maturities and currency pairs are calculated from delta neutral straddles, but the delta convention differs by tenor and currency pair. In the G-10 currency space, all tenors up to 12 months are either quoted with spot delta or premium adjusted spot delta, and tenors greater than 12 months are either quoted with forward delta or premium adjusted forward delta, depending on the currency-specific market quotation convention. We downloaded all available data from Bloomberg. Our data sample is constrained by the 36 exotic cross-volatilities. As an example, the cross volatility SEK/CAD is available only from October 2007 onwards. Hence, we employ option-price data covering the period October 2007-August 2015.

\section{THEORETICAL BACKGROUND}

\subsection{Implied and Realized Measures of Cross-Sectional RD}

Analogous to Chichernea et al. (2015) and Jiang (2010), who define the cross-sectional RD in the equity market as

$$
R D_{t}=\sqrt{\sum_{j=1}^{n} \omega_{j, t}\left(R_{j, t}^{\text {Equity }}-\overline{R_{j, t}^{\text {Equity }}}\right)^{2}}
$$

where $R_{j, t}^{\text {Equity }}$ is the return of stock $i$ at time $t$, our point of departure is the following measure:

$$
R D_{t}=\sqrt{\sum_{j=1}^{n} \omega_{j, t}\left(R_{j, t}^{\text {Spot }}-\overline{R_{j, t}^{\text {Spot }}}\right)^{2}}
$$

where $R_{j, t}^{\text {Spot }}$ is the spot exchange rate return of currency $j$ at time $t$ and $n=9$ and where $R_{J, t}^{\text {Spot }}$ is an equally weighted basket of $n$ currencies. From Equation (1) it follows that the same dispersion measure can also be expressed by the differences in variances:

$$
\begin{gathered}
\mathrm{E}\left[R D_{t}^{2}\right]=\sum_{j=1}^{n} \omega_{j, t} \sigma_{j, t}^{2}-\sigma_{J, t}^{2} \equiv f\left(\Omega_{t}\right) \\
\sigma_{J, t}^{2}=\omega_{t} \Omega_{t} \omega_{t}^{\prime} \\
\Omega_{t}=\operatorname{diag}\left(\sigma_{t}\right) \rho_{t} \operatorname{diag}\left(\sigma_{t}\right)
\end{gathered}
$$

where $\omega_{t}$ is the $1 \times n$ vector of equal weights at time $t$, where $\sigma_{j, t}^{2}$ is the variance of $j^{\text {th }}$ currency at time $t$, where $\operatorname{diag}\left(\sigma_{t}\right)$ is the $n \times n$ matrix with $n$ volatilities on the diagonal and zeros elsewhere at time $t$ and where $\rho_{t}$ is the $n \times n$ correlation matrix at time $t$ and where $\sigma_{t, t}^{2}$ is the variance of equally weighted basket of all $n$ currencies at time $t$. Our $R D$ measure $R D_{t}^{2}$ is thus a linear function of the basket's and components' variances.

${ }^{8}$ We refer to closing volatility as the closing price of the volatility. The closing prices are collected daily around 23.45 GMT, when the market is the quietest. 
Although our cross-sectional dispersion measure $R D_{t}^{2}$ is expressed as a function of variances, it is possible to calculate the option market expected dispersion measure-the implied dispersion-just as long as we know the implied volatilities of individual currencies and their implied correlation structure. The realized dispersion is thus fully replicable through positions on the variance of the index and the components. Hence, by replacing the volatility and correlation variables with market prices for the implied counterparts, we were able to observe the true market's risk neutral expectation for RD, which we call the implied cross-sectional RD impvar i $_{t, T}$

$$
\begin{gathered}
\operatorname{impvar}_{t, T}=\sum_{j=1}^{n} \omega_{j, t} \sigma_{j, t, T}^{2}-\sigma_{J, t, T}^{2} \\
\sigma_{J, t, T}^{2}=\omega_{t} \Omega_{t, T} \omega_{t}^{\prime} \\
\Omega_{t, T}=\operatorname{diag}\left(\sigma_{t, T}\right) \rho_{t, T} \operatorname{diag}\left(\sigma_{t, T}\right),
\end{gathered}
$$

where $T$ denotes a $T$ period conditional option market expectation on volatilities and correlations.

\subsection{Implied Volatilities and Implied Correlations}

Let us assume a triplet of currencies $x, y$, and $z$, and let $S_{x / y, t}, S_{x / z, t}$, and $S_{y / z, t}$ denote the corresponding triplet of logarithmic spot exchange rates at time $t$. In the absence of arbitrage, and in the existence of the holding triangular parity condition, the triplet of log exchange rates satisfies:

$$
s_{x / y, t}=s_{x / z, t}-s_{y / z, t}
$$

Then the following must also hold for the log foreign exchange returns:

$$
\Delta s_{x / y, t}=\Delta s_{x / z, t}-\Delta s_{y / z, t}
$$

Furthermore, we immediately see from Equation (9) that the conditional expected variance of $\Delta s_{x / y, t}$ for a horizon of $T$ days at time $t$ can be expressed as:

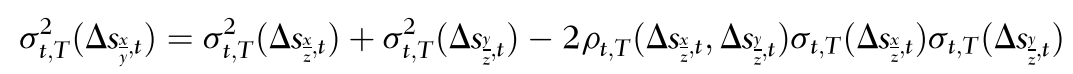

where the $\sigma_{t, T}(m)$ denotes a $T$ period expected conditional volatility of foreign exchange rate $m$ at time $t$, and where $\rho_{t, T}(m, n)$ is the conditional correlation between foreign exchange rate returns of $m$ and $n$ at time tover a horizon of $T$.

By rearranging Equation (10) on the conditional variance between two currency logreturns, and substituting the volatilities with the implied market volatility quotes, period $T$ ex ante correlation estimates from the currency option prices at time $t$ can be extracted:

$$
\rho_{t, T}\left(\Delta s_{\frac{x}{z}, t}, \Delta s_{\frac{y}{z}, t}\right)=\frac{\sigma_{t, T}^{2}\left(\Delta s_{\frac{x}{z}, t}\right)+\sigma_{t, T}^{2}\left(\Delta s_{\frac{z}{z}, t}\right)-\sigma_{t, T}^{2}\left(\Delta s_{\underline{y}, t}\right)}{2 \sigma_{t, T}\left(\Delta s_{\bar{z}, t}^{x}\right) \sigma_{t, T}\left(\Delta s_{\bar{z}, t}\right)}
$$

The volatility quotes in Equation (11) are the market's implied volatility quotes backed out from the famous Garman and Kohlhagen (1983) formula: 


$$
\begin{gathered}
c_{t, T}=e^{r_{d, t, T(T-t)}\left[F_{t, T} N\left(d_{1}\right)-K N\left(d_{2}\right)\right]} \\
d_{1}=\frac{\ln \left(\frac{F_{t, T}}{K}\right)+\frac{1}{2} \sigma_{t, T}^{2}(T-t)}{\sigma_{t, T} \sqrt{T-t}} \\
d_{2}=d_{1}-\sigma_{t, T} \sqrt{T-t}
\end{gathered}
$$

where $F_{t, T}$ is the $T$ period foreign exchange forward price at time $t, r_{d, t, T}$ is the $T$ period domestic interest rate at time $t, K$ is the strike price of an option and $N(\cdot)$ is the normal CDF.

Option prices, as inherently forward-looking indicators, implicitly provide information on the market expectations of future asset price developments. This option-implied correlation measure is an ex ante estimate of the magnitude of co-movements between two exchange rates. Assuming that market participants are rational, option prices, and thereby implied correlations, should incorporate all the available information that is relevant to forming expectations about future exchange rate developments.

If option markets are efficient, then we would expect that

$$
E\left[\sum_{j=1}^{n} \omega_{j, t} \sigma_{j, t}^{2}-\sigma_{J, t}^{2}\right]=\mathrm{E}\left[\sum_{j=1}^{n} \omega_{j, t} \sigma_{j, t, T}^{2}-\sigma_{J, t, T}^{2}\right] .
$$

\section{EMPIRICAL ANALYSIS}

\subsection{Descriptive Statistics}

Table I presents the descriptive statistics for the implied and realized measure of crosssectional return variance. The sample period is from period October 2007-August 2015. Statistics for the implied and log-implied cross-sectional variance series based on option data with 1- and 3-month maturities are presented in Panel A. Statistics for the implied and logimplied cross-sectional variance series based on option data with 3-and 6-month maturities are presented in Panel B, whereas Panel C presents the statistics for the realized and logrealized cross-sectional variance series.

Starting with the sample means, we found that both average realized and average logrealized cross-sectional return variance exceed all corresponding implied measures. The data reveal some interesting patterns. First, we observed that the skewness of the implied measures (and log-implied measures) decreased as the maturity increases. Assuming that cross-sectional return variance is a macroeconomic state variable, and interpreting the skewness as economic crash risk, this result implies that market participants generally expect more stable economic conditions in the long-term than in the short-term. Similarly, we observed that the excess kurtosis decreased as the maturity increases. Testing for normality (unreported) showed that the time series in logs are statistically distributed as normal, irrespective of whether we consider the log-realized or log-implied distributions.

To assess the time series properties of those measures, we followed Christensen and Prabhala (1998) and fit ARIMA $(p, d, q)$ models of the form

$$
\Phi(B)\left(\Delta^{d} x_{t}-\mu\right)=\Theta(B) \varepsilon_{t}
$$

where $x_{t}$ represents one of the log-dispersion series. In Equation (16), the parameter $\mu$ is the mean, $\varepsilon_{t}$ is white noise, $\Phi$ and $\Theta$ are polynomials of order $p$ and $q$ in $B$, the backshift operator 
TABLE I

Descriptive Statistics

Panel A: Implied Cross-Sectional Variances and Log-Implied Cross-Sectional Variances for 1- and 3-Month Horizons

\begin{tabular}{lcccc}
\hline Statistic & $\begin{array}{c}\text { Implied } \\
\text { Cross-Sectional } \\
\text { Variance 1 Month }\end{array}$ & $\begin{array}{c}\text { Log-implied } \\
\text { Cross-Sectional Variance } \\
\text { 1 Month }\end{array}$ & $\begin{array}{c}\text { Implied } \\
\text { Cross-Sectional } \\
\text { Variance 3 Months }\end{array}$ & $\begin{array}{c}\text { Log-implied } \\
\text { Cross-Sectional Variance } \\
\text { 3 Months }\end{array}$ \\
\hline Mean & 0.0153 & -4.4060 & 0.0152 & -4.3679 \\
Variance & 0.0127 & 0.6563 & 0.0102 & 0.5993 \\
Skewness & 2.9434 & 0.3098 & 1.9163 & 0.1390 \\
Kurtosis & 14.3859 & 3.3513 & 7.3497 & 2.8546 \\
\hline
\end{tabular}

Panel B: Implied Cross-Sectional Variances and Log-Implied Cross-Sectional Variances for 6 and 12 Months Horizons

\begin{tabular}{lcccc}
\hline Statistic & $\begin{array}{c}\text { Implied } \\
\text { Cross-Sectional } \\
\text { Variance 6 Months }\end{array}$ & $\begin{array}{c}\text { Log-implied } \\
\text { Cross-Sectional } \\
\text { Variance 6 Months }\end{array}$ & $\begin{array}{c}\text { Implied } \\
\text { Cross-Sectional } \\
\text { Variance 12 Months }\end{array}$ & $\begin{array}{c}\text { Log-implied } \\
\text { Cross-Sectional Variance } \\
\text { 12 Months }\end{array}$ \\
\hline Mean & 0.0154 & -4.3215 & 0.0157 & -4.2691 \\
Variance & 0.0087 & 0.5449 & 0.0076 & 0.4856 \\
Skewness & 1.3111 & 0.0278 & 0.8382 & -0.0373 \\
Kurtosis & 4.7556 & 2.4909 & 3.2150 & 2.1459 \\
\hline
\end{tabular}

Panel C: Realized Cross-Sectional Variance and Log-Realized Cross-Sectional Variance

\begin{tabular}{lcc} 
Statistic & Realized Cross-Sectional Variance & Log-Realized Cross-Sectional Variance \\
\hline Mean & 0.0174 & -4.6806 \\
Variance & 0.0247 & 1.1147 \\
Skewness & 3.3898 & 0.1811 \\
Kurtosis & 17.9668 & 2.8401 \\
\hline
\end{tabular}

Descriptive statistics for monthly time series of natural logarithms of implied cross-sectional variances and realized crosssectional variances for all USD-crosses in G10 space. Here, implied volatilities are quoted each month using the GarmanKohlhagen formula. All the quoted volatility levels in all four maturities and 45 currency pairs are calculated from delta neutral straddles, the delta convention, however, differs with tenor and currency pair. In the G10 space, all tenors up to 12 months are either quoted with spot delta or premium adjusted spot delta, and tenors greater than 12 months are either quoted with forward delta or premium adjusted forward delta, depending on the currency-specific market quotation convention. In order to calculate the implied dispersion, we need to calculate basket volatility for the nine USD-crosses in the G10 space, for which we need to calculate the implied correlation structure using implied volatilities for all $45 \mathrm{FX}$-crosses in the G10 space. As the currency triangle, the natural no arbitrage condition between spot prices (i.e., if $E U R U S D=g$ and $U S D J P Y=h, E U R J P Y=g^{*} h$ ), has to exist, also the FX volatility has to be directly determined by the volatilities of the other two spot rate processes, together with the correlation between Brownian motions (i.e., $\sigma_{i, j}^{2}=\sigma_{i}^{2}+\sigma_{i}^{2}-2 \rho_{i, j} \sigma_{i} \sigma_{j}$ ). This means we obtained implied correlations from implied volatility quotes for the three $\mathrm{FX}$ spot rates comprising the currency triangle. Employing the full implied correlation structure, we obtained the G10 basket variance, $\sigma_{J, t, T}^{2}=\omega_{t} \Omega_{t, T} \omega_{t}^{\prime}$, where $\omega$ is the $1 \times 9$ vector of equal weights, $\Omega_{t, T}=\operatorname{diag}\left(\sigma_{t, T}\right) \rho_{t, T} \operatorname{diag}\left(\sigma_{t, T}\right)$, where $\operatorname{diag}\left(\sigma_{t, T}\right)$ is a $9 \times 9$ matrix with nine implied volatilities on the diagonal, and $\rho_{t, T}$ is the $9 \times 9$ implied correlation matrix. The implied dispersion (impvar) is then imp $\operatorname{var}_{t, T}=\Sigma_{j=1}^{n} \omega_{j}, \sigma_{j, t, T}^{2}-\sigma_{j, t, T}^{2}$. Realized dispersion is the annualized cross-sectional variance of the G10 returns at a given time $t$.

defined by $B x_{t}=x_{t-1}$, and $\Delta=1-B$ is the first-difference operator. Following Christensen and Prabhala (1998), we fit the time series models to the log-dispersion series rather than the levels because of the normality issue.

Table II Panel A displays the results for the implied dispersion series based on optionprice data with 1-month maturity. The Box-Pierce (1970) portmanteau statistic is in favor of 


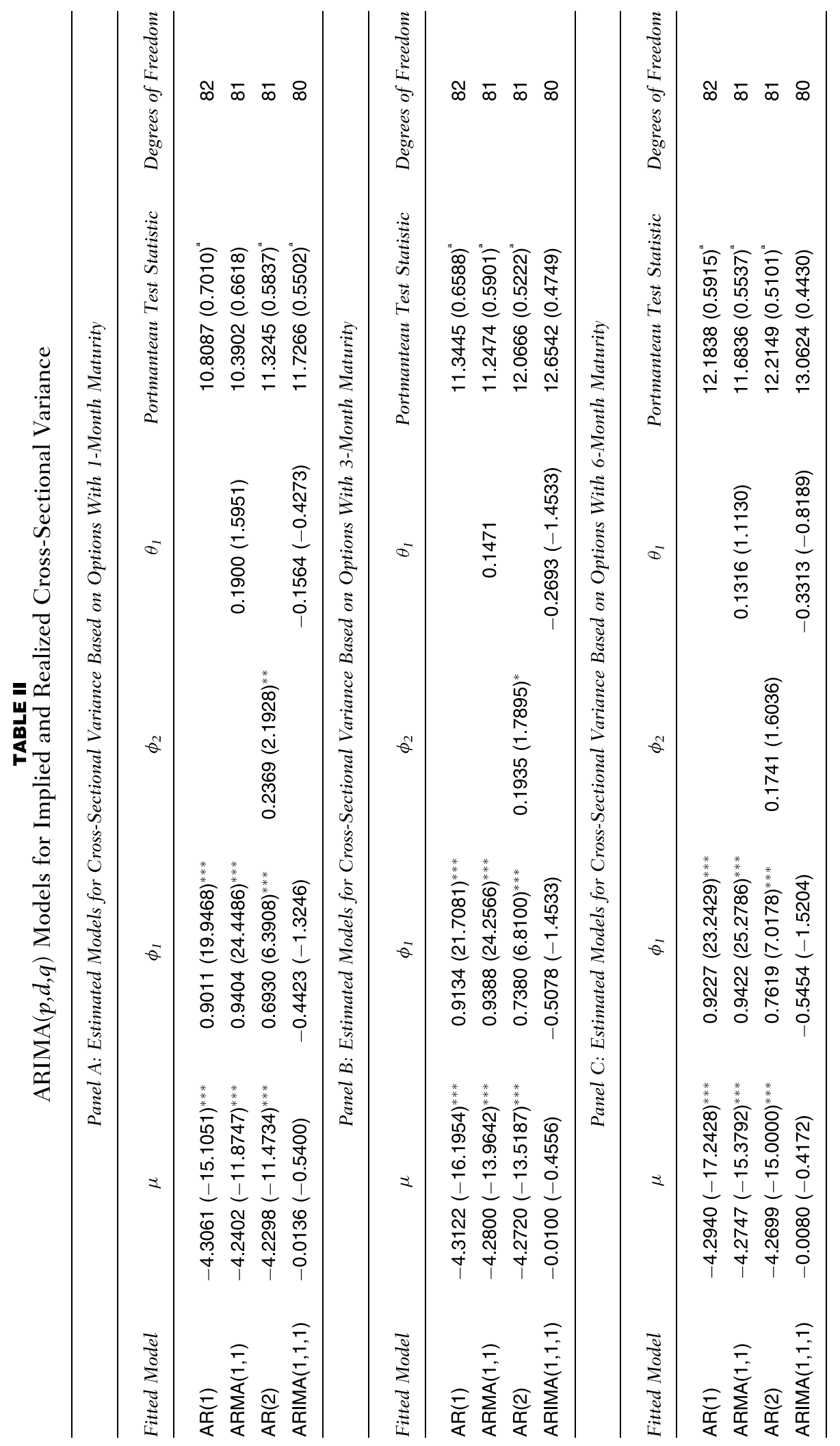




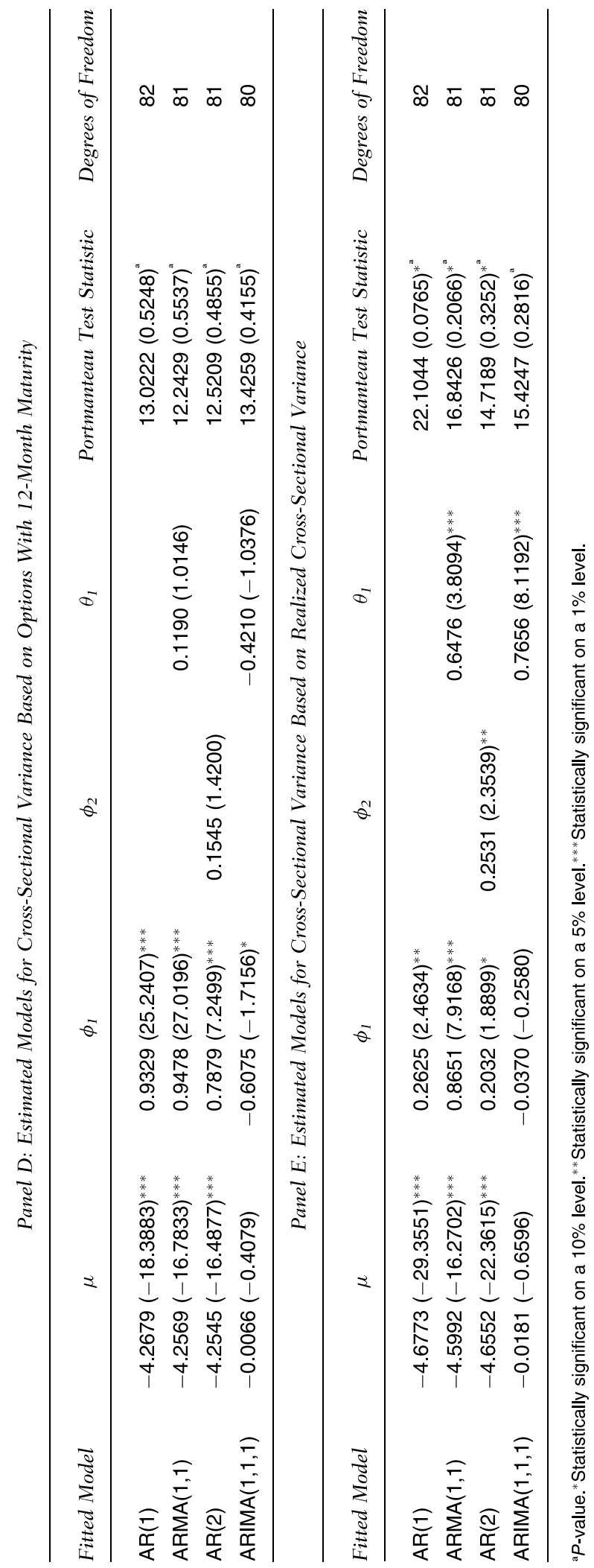


the AR (1) specification and indicates the absence of remaining autocorrelation. We observed the same patterns for the implied dispersion series based on option-price data with 3- and 6month maturities, as shown in Panel B and C of Table II. Even though the $P$-value of 0.5537 is marginally larger for the ARMA $(1,1)$ specification for the implied dispersion series based on option-price data with 12-month maturity, as shown in Panel D of Table II the estimated parameter $\theta_{1}$ is statistically not different from zero which points toward the $\operatorname{AR}(1)$ model being the most accurate and the parsimonious model. Investigating the realized cross-sectional dispersion, we observed that the first-order autocorrelation coefficient becomes only marginally significant after we included the second lag. However, the portmanteau statistic of 22.10 (the corresponding $P$-value is 0.0765 ) suggests that the $\operatorname{AR}(1)$ model captures the autocorrelation accurately on a common 5\% significance level, whereas the portmanteau statistic of the $\operatorname{AR}(2)$ model specification indicates the absence of remaining autocorrelation on a $10 \%$ significance level. Interestingly, the economic magnitude of the estimated parameter $\widehat{\phi_{1}}$ varies between 0.90 and 0.93 when considering the implied dispersion series, which suggests a high degree of persistence. Considering the realized cross-sectional dispersion, the economic magnitude of $\hat{\phi}_{2}$ which is 0.25 indicates that the realized process is relatively far less persistent. Below, we have chosen the simple AR(1) model as a benchmark model for the realized cross-sectional dispersion because it is the most parsimonious model that does not the reject the null hypothesis of no remaining autocorrelation on a common 5\% significance level.

\subsection{The Relation Between Implied and Realized Cross-Sectional Return Variance}

The same argument concerning the measurement error of estimating implied volatility as is detailed in Christensen and Prabhala (1998, Section 2.4) could also affect our analysis. For instance, one source of measurement error could be the bid-ask spreads in option prices. On the other hand, we minimize these sources of measurement error because we only account for ATM options. Another source of measurement error could be that the Black-Scholes formula in Equation (12) assumes a log-normal diffusion process with deterministic crosssectional return variance. In the presence of jumps in the process, the Black-Scholes formula is misspecified, which would exacerbate the errors-in-variable problem if Black-Scholes implied cross-sectional return variance is used as cross-sectional return variance forecast. As documented by Christensen and Prabhala (1998), a study of the relation between implied and realized cross-sectional return variance is meaningful, but must be interpreted differently. However, we apply the same argument as Christensen and Prabhala (1998, p.133), namely that our study can be regarded as a simple test of whether option prices are informative on future cross-sectional return variance, "without necessarily drawing any inferences about the efficiency of option markets."

In this section, we investigate the information content of implied cross-sectional return variance by employing various model specifications. Our results offer strong evidence that implied cross-sectional return variance contains incremental information beyond that occurring in past-realized cross-sectional return variance. Robustness checks support our findings. In a similar manner to Christensen and Prabhala (1998), we started our analysis by constructing a standard regression model of the form

$$
\text { realvar }_{t}=\alpha_{0}+\alpha_{1} \text { impvar }_{t \mid t-k}+\alpha_{2} \text { realvar }_{t-1}+\varepsilon_{t}
$$

where $\operatorname{impvar}_{t \mid t-k}$ denotes the natural logarithm of implied cross-sectional variances as described in Table I, with maturities $k=\{1,3,6,12\}$. For instance, if $k=1$, then the model accounts for impvar $_{t-1}$ that is the predicted variance for time $t$ using the 6-month maturities options in month $t-1$ and so forth. 
At least three hypotheses can be tested using Equation (17). First, if implied cross-sectional return variance contains some information about future cross-sectional return variance, $\alpha_{1}$ should be a value other than zero. Furthermore, if implied cross-sectional return variance is an unbiased forecast of its realized counterpart, we should find that $\alpha_{0}=0$ and $\alpha_{1}=1$. Finally, if implied cross-sectional return variance is efficient, the residuals $\varepsilon_{t}$ should follow a white noise process that is uncorrelated with any other variable that may be within the market's information set. Ordinary least-squares estimates of Equation (17) are reported in Table III. The data on the first row of Table III show that past-realized cross-sectional return variance is a biased estimator. The economic magnitude of the intercept is -3.47 with a $t$-statistic of -6.31 indicating statistical significance on any level. The Breusch-Godfrey serial correlation LM test accounting for one lag (unreported) causes the null hypothesis of no remaining autocorrelation $(P$-value $0.0025)$ to be rejected, which indicates that the residuals exhibit autocorrelation.

The data on the second row of Table III show that implied cross-sectional return variance using option prices with 1 -month maturity performs remarkably well. The intercept is statistically not different from zero and the economic magnitude of the parameter $\alpha_{1}$ is 0.82 . In contrast to past-realized cross-sectional RD that explains only $5.78 \%$ of realized cross-sectional $\mathrm{RD}$, the adjusted $R$-squared for the model employing an implied measure using the option with 1-month maturity explains $22.94 \%$ of the variation in realized crosssectional return variance. Even if an $F$-test disproves the joint hypothesis $\alpha_{0}=0$ and $\alpha_{1}=1$ ( $P$-value is 0.0183 ), testing the residuals for remaining autocorrelation shows that this model generates residuals that follow a white noise process (the $P$-value is 0.4109 ). This result implies that implied cross-sectional return variance computed with option-price data with 1month maturity appears to be a biased forecast of future volatility. However, implied crosssectional RD offers some information about future cross-sectional RD because the parameter $\alpha_{1}$ is economically more than three times larger than the corresponding parameter of pastrealized cross-sectional $\mathrm{RD}$, and is statistically significant on any level. The data on the third row of Table III show that this result does not change even if we control for past-realized cross-sectional return variance. Once implied cross-sectional return variance is accounted for, the past-realized counterpart lacks any predictive power.

Rows four to ten provide evidence that as we move to implied cross-sectional return variance measures compounded by using option-price data from 3- to 12-month maturity, the economic magnitude of implied cross-sectional return variance as a predictor for the realized measure decreases whereas the intercept increases. This result is less surprising because using option-price data with longer maturity entails more uncertainty. To this point, our results indicate that the $\mathrm{G} 10$ implied cross-sectional return variance has far more predictive power than the past-realized measure, whether that power is judged by the magnitude of the regression slope or by the $R$-squared of each of the regressions.

\subsection{Instrument Variable (IV) Estimation}

In this section, we analyze an alternative specification of the form

$$
\begin{gathered}
\operatorname{realvar}_{t}=\alpha_{0}+\alpha_{1} \operatorname{impvar}_{t \mid t-1}+\alpha_{2} \text { realvar }_{t-1}+\varepsilon_{t}, \text { with } \\
\operatorname{impvar}_{t \mid t-1}=\beta_{0}+\beta_{1} \operatorname{impvar}_{t-1 \mid t-2}+\beta_{2} \text { realvar }_{t-1}+u_{t}, \text { and } \\
\operatorname{realvar}_{t}=\alpha_{0}+\alpha_{1} \operatorname{impvar}_{t \mid t-3}+\alpha_{2} \text { realvar }_{t-1}+\varepsilon_{t}, \text { with } \\
\operatorname{impvar}_{t \mid t-3}=\beta_{0}+\beta_{1} \text { impvar }_{t-1 \mid t-4}+\beta_{2} \text { realvar }_{t-1}+u_{t},
\end{gathered}
$$

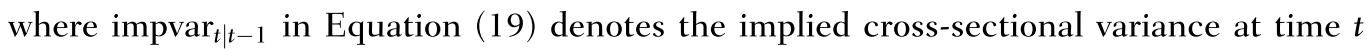
based on the options with 1 -month maturity from the previous month (i.e., $t-1)$ impvar $_{t-1 \mid t-1}$ 


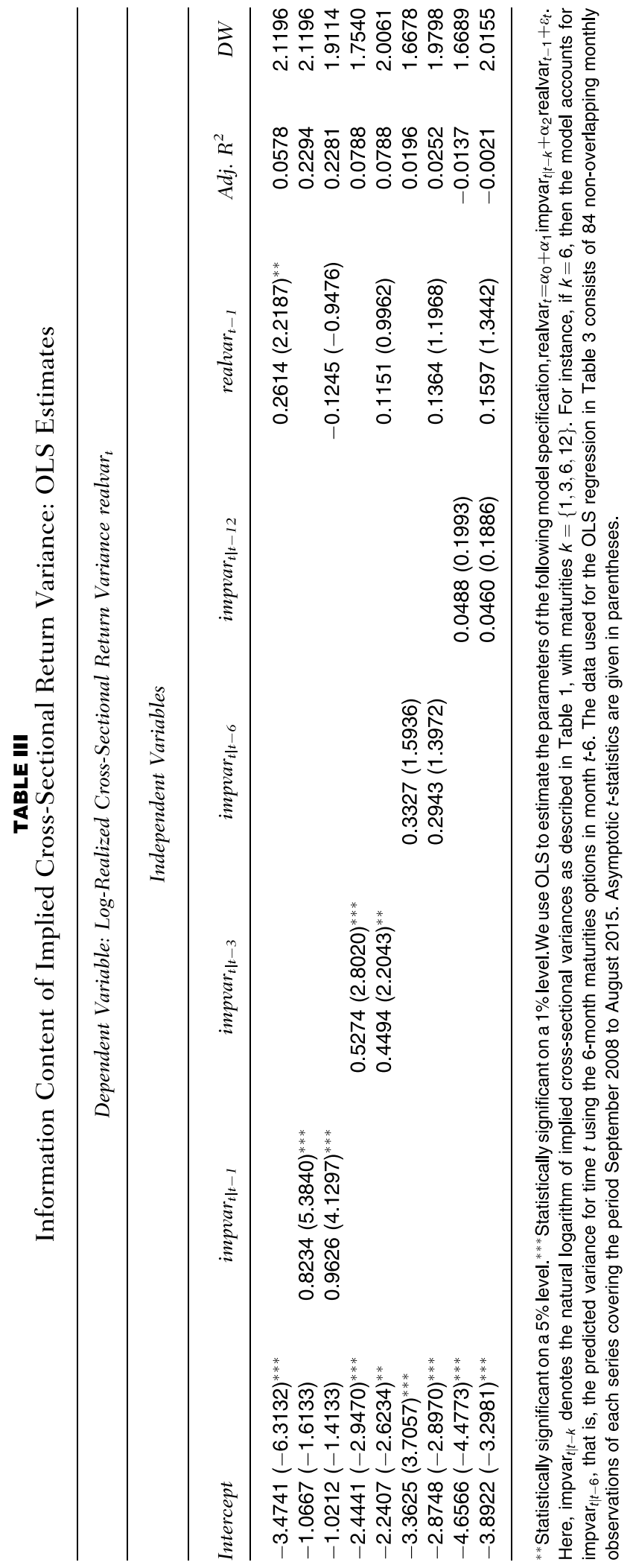


denotes the implied cross-sectional variance at time $t$ - 1 based on the options with 1 -month maturity from the previous month (i.e., $t-2$ ) and realvar $_{t-1}$ is the lagged realized crosssectional variance. Moreover, the predicted values for the implied cross-sectional variance in Equation (18) are given by imp $\widehat{v a r}_{t \mid t-1}=\widehat{\beta_{0}}+\widehat{\beta_{1}}$ impvar $_{t-1 \mid t-2}+\widehat{\beta_{2}}$ realvar $_{t-1}$. Similarly, impvar $_{t \mid t-3}$ in Equation (21) denotes the implied cross-sectional variance at time $t$ based on the options with 3-month maturity from 3 months previously (i.e., $t$-3), impvar $_{t-1 \mid t-4}$ denotes the implied cross-sectional variance at time $t$-1 based on the options with 3-month maturity from the previous 3 -month period (i.e., $t-4)$ and realvar $_{t-1}$ is the lagged realized cross-sectional variance. The predicted values for the implied cross-sectional variance in Equation (20) are given by imp $\widehat{v a r}_{t \mid t-3}=\widehat{\beta_{0}}+\widehat{\beta_{1}}$ impvar $_{t-1 \mid t-4}+\widehat{\beta_{2}}$ realvar $_{t-1}$.

If option prices reflect information for cross-sectional return variance, implied crosssectional return variance should not only predict future cross-sectional return variance but should also itself endogenously depend on past cross-sectional return variance, because past and future cross-sectional return variance are positively related. To test this effect, we used the models in Equations (18-21) that are similar to those in the work of Christensen and Prabhala (1998, Section 3.2). We use the IV framework for the same reasons as Christensen and Prabhala (1998) did in the context of investigating the predictive power of implied volatility for realized volatility. ${ }^{9}$ Although the results in the previous section show that implied cross-sectional return variance based on option data with 1- and 3-month maturity have the highest predictive power, we exclusively focus on those in this section. Equations (18) and (19) provide the IV framework for analyzing the implied cross-sectional return variance based on option-price data with 1-month maturity, whereas Equations (20) and (21) provide the corresponding framework for option-price data with 3-month maturity.

The IV procedure requires specifying an instrument for implied volatility. Pastimplied volatility impvar ${ }_{t \mid t-1}$ is a natural candidate simply because it is correlated with true time $t$ implied cross-sectional return variance, as shown in section 4.1 , but it is plausible that it is unrelated to the measurement error associated with implied cross-sectional return variance sampled 1 month later. ${ }^{10}$ Table IV reports the IV estimates employing the model for Equations (18) and (19), which is based on option-price data with 1-month maturity. Panel A of Table IV reports the estimates of the first-step regression, as given in Equation (19), whereas Panel B of Table IV reports the second-stage regression. We observe that past-implied cross-sectional return variance explains $80.75 \%$ of the variation of future-implied cross-sectional return variance. The point estimate for $\beta_{1}$ is 0.93 , indicating a high degree of autocorrelation. Strikingly, an F-test could not disprove the joint hypothesis $\beta_{0}=0, \beta_{1}=1$, and $\beta_{2}=0$ on a common $5 \%$ significance level ( $P$-value is 0.0947), which indicates that with this IV framework implied cross-sectional return variance is an unbiased predictor. Moreover, employing the Breusch-Godfrey serial correlation LM test accounting for one lag (unreported) shows that the null hypothesis of no remaining autocorrelation in the residuals $u_{t}(P$-value 0.0659$)$ cannot be rejected on a

\footnotetext{
${ }^{9} \mathrm{~A}$ more detailed discussion is provided in Christensen and Prabhala (1998, Section 3.2).

${ }^{10}$ The same reasons that Christensen and Prabhala (1998, p.137) attribute to a potential measurement error in the implied and realized volatility context may be present in our analysis. Specifically, they argue that the measurement error could be attributed to nonsynchronous measurement of option prices and index levels, early exercise and dividends, which are ignored in the Black-Scholes formula, bid-ask spreads, the "wild-card" option, or misspecification of the stochastic process governing index returns. Concerning nonsynchronous measurement of option prices and index levels, the closing cash index level precedes the level implied in option prices by up to 15 minutes, due to different closing times on the two exchanges. However, the authors argue that the difference between the cash market closing and the level implied in closing option prices is unlikely to be correlated at a 1month lag.
} 
TABLE IV

Information Content of Implied Cross-Sectional RD Based on Options With 1-Month Maturity in the G-10 Currency Space

\begin{tabular}{|c|c|c|c|c|}
\hline \multicolumn{5}{|c|}{ Panel A: First Stage Regression } \\
\hline \multicolumn{5}{|c|}{ Dependent Variable: impvar $_{t \mid t-1}$} \\
\hline \multicolumn{3}{|c|}{ Independent Variables } & \multirow[t]{2}{*}{$\operatorname{Adj} . R^{2}$} & \multirow[t]{2}{*}{$D W$} \\
\hline Intercept & impvar $_{t-1 \mid t-2}$ & realvar $_{t-1}$ & & \\
\hline$-0.4887(-2.2882)^{* *}$ & $0.9322(14.3839)^{* * *}$ & $-0.0385(-1.0088)$ & 0.8075 & 2.1285 \\
\hline \multicolumn{5}{|c|}{ Panel B: First Stage Regression } \\
\hline \multicolumn{5}{|c|}{ Dependent Variable: realvar ${ }_{t}$} \\
\hline \multicolumn{3}{|c|}{ Independent Variables } & \multirow[t]{2}{*}{$\operatorname{Adj} . R^{2}$} & \multirow[t]{2}{*}{$D W$} \\
\hline Intercept & $\operatorname{impvar} t \mid t-1$ & realvar $_{t-1}$ & & \\
\hline$-1.5644(-1.8843)^{*}$ & $0.7174(3.8485)^{* * *}$ & & 0.1457 & 1.8928 \\
\hline$-1.5322(-1.8311)^{*}$ & $0.6656(3.0945)^{* * *}$ & $0.0556(0.4895)$ & 0.1375 & 2.0051 \\
\hline
\end{tabular}

*Statistically significant on a $10 \%$ level.

${ }^{* *}$ Statistically significant on a $5 \%$ level.

***Statistically significant on a $1 \%$ level.

Panel A reports OLS estimates of the specification impvar $_{t \mid t-1}=\beta_{0}+\beta_{1}$ impvar $_{t-1 \mid t-2}+\beta_{2}$ realvar $_{t-1}+u_{t}$,

where impvar ${ }_{t \mid t-1}$ denotes the implied cross-sectional variance at time $t$ based on the options with 1-month maturity from the previous month (i.e., $t-1$ ) impvar ${ }_{t-1 \mid t-1}$ denotes the implied cross-sectional variance at time $t-1$ based on the options with 1-month maturity from the previous month (i.e., $t-2)$ and realvar $t_{t-1}$ is the lagged realized cross-sectional variance. The predicted values for the implied cross-sectional variance is the given by impvar $\widehat{t \mid t-1}_{1}=\widehat{\beta_{0}}+{\widehat{\beta_{1}}}_{\text {impvar }_{t-1 \mid t-2}}+{\widehat{\beta_{2}}}_{\text {realvar }_{t-1}}$.

Panel $B$ reports instrumental variable (IV) estimates of the specification

realvar $_{t}=\alpha_{0}+\alpha_{1}$ impvar $_{t \mid t-1}+\alpha_{2}$ realvar $_{t-1}+\varepsilon_{t}$,

using either the predicted implied cross-sectional variance of the first path regression impvar ${ }_{t \mid t-1}$ as a regressor or both the predicted implied cross-sectional variance impvar ${ }_{t \mid t-1}$ and the lagged realized cross-sectional variance realvar ${ }_{t-1}$ and the same data as in Panel A. Asymptotic $t$-statistics are given in parentheses.

common 5\% significance level which indicates that past-implied cross-sectional return variance is not only an unbiased but also an efficient predictor for future-implied crosssectional RD.

Next, we turn our attention to the second-state estimates reported in Panel B of Table IV. Even though $F$-tests (unreported) cannot reject the joint hypothesis $\beta_{0}=0$, and $\beta_{1}=1$ (for the model in the second row in Panel B) or $\beta_{0}=0, \beta_{1}=1$, and $\beta_{2}=0$ (for the model in the third row in Panel B) on a common 5\% significance level $(P$-values are 0.0066 and 0.0168), applying the Breusch-Godfrey serial correlation LM test accounting for one lag to the residuals $\varepsilon_{t}$ (unreported) shows that irrespective of whether or not lagged pastimplied cross-sectional return variance is accounted for, the model generate residuals that follow a white noise because the null hypotheses of no remaining autocorrelation cannot be rejected ( $P$-values 0.6554 and 0.8679$)$. Overall, the IV framework provides strong support for the ordinary least squares (OLS) regression framework in showing that implied 
TABLE V

Information Content of Implied Cross-Sectional RD Based on Options With 3-Month Maturity in the G-10 Currency Space

\begin{tabular}{|c|c|c|c|c|}
\hline \multicolumn{5}{|c|}{ Panel A: First Stage Regression } \\
\hline \multicolumn{5}{|c|}{ Dependent Variable: impvar $_{t \mid t-1}$} \\
\hline \multicolumn{3}{|c|}{ Independent variables } & \multirow[t]{2}{*}{ Adj. $R^{2}$} & \multirow[t]{2}{*}{$D W$} \\
\hline Intercept & impvar $_{t-1 \mid t-4}$ & realvar $_{t-1}$ & & \\
\hline$-0.3799(-1.9608)^{*}$ & $0.9370(16.6049)^{* * *}$ & $-0.0208(-0.6839)$ & 0.8403 & 2.0678 \\
\hline \multicolumn{5}{|c|}{ Panel B: First Stage Regression } \\
\hline \multicolumn{5}{|c|}{ Dependent Variable: realvar ${ }_{t}$} \\
\hline \multicolumn{3}{|c|}{ Independent Variables } & \multirow[t]{2}{*}{ Adj. $R^{2}$} & \multirow[t]{2}{*}{$D W$} \\
\hline Intercept & $\operatorname{impvar}{ }_{t \mid t-3}$ & realvar $_{t-1}$ & & \\
\hline$-1.5072(-1.7077)^{*}$ & $0.7429(3.6821)^{* * *}$ & & 0.1342 & 1.8542 \\
\hline$-1.4664(-1.6515)$ & $0.6726(2.9352)^{* * *}$ & $0.0738(0.6561)$ & 0.1280 & 2.0102 \\
\hline
\end{tabular}

* Statistically significant on a $10 \%$ level.

${ }^{* *}$ Statistically significant on a $5 \%$ level.

${ }^{* * *}$ Statistically significant on a $1 \%$ level.

Panel A reports OLS estimates of the specification

impvar $_{t \mid t-1}=\beta_{0}+\beta_{1}$ impvar $_{t-1 \mid t-4}+\beta_{2}$ realvar $_{t-1}+u_{t}$,

where impvar ${ }_{t \mid t-3}$ denotes the implied cross-sectional variance at time $t$ based on the options with 3-month maturity from 3 months ago (i.e., $t-3$ ), impvar ${ }_{t-1 \mid t-4}$ denotes the implied cross-sectional variance at time $t-1$ based on the options with 3 -month maturity from the previous 3-month period (i.e., $t-4$ ) and realvar $r_{t-1}$ is the lagged realized cross-sectional variance. The predicted values for the implied cross-sectional variance is the given by impvar ${ }_{t \mid t-3}=\widehat{\beta_{0}}+\widehat{\beta_{1}}$ impvar $_{t-1 \mid t-4}+\widehat{\beta_{2}}$ realvar $_{t-1}$.

Panel $B$ reports instrumental variable (IV) estimates of the specification

realvar $_{t}=\alpha_{0}+\alpha_{1}$ impvar $_{t \mid t-3}+\alpha_{2}$ realvar $_{t-1}+\varepsilon_{t}$,

using either the predicted implied cross-sectional variance of the first path regression impvar $\widehat{t}_{t \mid-3}$ as a regressor or both the predicted implied cross-sectional variance impvar ${ }_{t \mid t-3}$ and the lagged realized cross-sectional variance realvar ${ }_{t-1}$ and the same data as in Panel A. Asymptotic $t$-statistics are given in parentheses.

cross-sectional return variance is a biased predictor of future cross-sectional return variance; nevertheless, it far outperforms the past-realized measure. Table $\mathrm{V}$ shows the results of repeating the same analysis using options with a 3-month maturity. The results remain virtually unchanged. ${ }^{11}$

\subsection{Robustness Check: Bootstrapping the OLS Regression Models}

In this section, we reexamine the information content of implied cross-sectional return variance through the non-parametric bootstrapping procedure for linear regression models as

\footnotetext{
${ }^{11}$ Additional Tables that report the F-tests and Breusch-Godfrey serial correlation LM test in detail are available upon request.
} 
detailed in Godfrey (2009, Section 3.4). We conducted successive F-tests of the null hypothesis that the parameter estimate is zero for each of the parameters and every model. We constructed artificial bootstrap samples of the empirical density function under the null hypothesis, that is, we employed the restricted models. We report the corresponding bootstrapped $P$-values for the parameter estimates of Equations (17-21) using 1000 bootstrap replications in Table VI. In general, the data in Table VI provide strong support for the findings discussed previously; nevertheless, there are some differences. First, considering the model given in Equation (17), the first row in Table VI reveals that the past-realized crosssectional variance is statistically not significant. In all model specifications, apart from the model given in Equation (18), the past-realized cross-sectional variance is statistically not different from zero. The empirical outcome that the parameter estimate of the past-realized cross-sectional variance is significant in the model of Equation (18) can be attributed to a multicollinearity issue: A correlation analysis reveals that the correlation between pastrealized cross-sectional return variance and option-implied cross-sectional variance is 0.80 ,

\section{TABLE VI}

Information Content of Implied Cross-Sectional Return Variance: Bootstrapped OLS Estimates Dependent Variable: Log-Realized Cross-Sectional Return Variance Realvar ${ }_{t}$

\begin{tabular}{|c|c|c|c|c|c|}
\hline \multicolumn{6}{|c|}{ Independent Variables } \\
\hline Intercept ${ }^{a}$ & $\operatorname{impvar}_{t \mid t-1}^{a}$ & $\operatorname{impvar}_{t \mid t-3}{ }^{a}$ & $\operatorname{impvar}_{t \mid t-6}{ }^{a}$ & $\operatorname{impvar}_{t \mid t-12^{a}}$ & $\operatorname{impvar}_{t \mid t-1}{ }^{a}$ \\
\hline-3.4741 & & & & & 0.2614 \\
\hline$(0.0000)^{* * *}$ & & & & & $(0.1610)$ \\
\hline-1.0667 & 0.8324 & & & & \\
\hline$(0.0520)^{*}$ & $(0.0070)^{* * *}$ & & & & \\
\hline-1.0212 & 0.9626 & & & & -0.1245 \\
\hline$(0.1910)$ & $(0.0000)^{* * *}$ & & & & $(0.0200)^{* *}$ \\
\hline-2.4441 & & 0.5274 & & & \\
\hline$(0.1530)$ & & $(0.0010)^{* * *}$ & & & \\
\hline-2.2407 & & 0.4494 & & & 0.1151 \\
\hline$(0.1650)$ & & $(0.0020)^{* * *}$ & & & $(0.7020)$ \\
\hline-3.3625 & & & 0.3327 & & \\
\hline$(0.0230)^{* *}$ & & & $(0.0760)^{*}$ & & \\
\hline-2.8748 & & & 0.2943 & & 0.1364 \\
\hline$(0.0260)^{* *}$ & & & $(0.0660)^{*}$ & & $(0.6380)$ \\
\hline-4.6566 & & & & 0.0488 & \\
\hline$(0.0050)^{* * *}$ & & & & $(0.5950)$ & \\
\hline-3.8922 & & & & 0.0460 & 0.1597 \\
\hline$(0.0150)^{* *}$ & & & & $(0.6530)$ & $(0.6800)$ \\
\hline
\end{tabular}

" $P$-values are given in parentheses.

* Statistically significant on a $5 \%$ level.

** Statistically significant on a $5 \%$ level.

*** Statistically significant on a $1 \%$ level.

We use OLS to estimate the parameters of the following model specification,

realvar $_{t}=\alpha_{0}+\alpha_{1}$ imp var $_{t \mid t-k}+\alpha_{2}$ realvar $_{t-1}+\varepsilon_{t}$.

Here, impvar ${ }_{t \mid t-k}$ denotes the natural logarithm of implied cross-sectional variances as described in Table 1 , with maturities $\mathrm{k}=$ $\{1,3,6,12\}$. For instance, if $k=6$, then the model accounts for impvar ${ }_{t \mid t-6}$, that is, the predicted variance for time $t$ using the $6-$ months maturities options in month $t-6$. The data used for the OLS regression in Table 3 consists of 84 non-overlapping monthly observations of each series covering the period September 2008 to August 2015. We employ the bootstrap approach as detailed in Godfrey (2009, Section 3.4) and construct 1000 artificial samples by using the empirical density function under the null hypothesis. Bootstrapped $P$-values are given in parentheses. 
whereas the correlation between realized cross-sectional return variance and implied crosssectional return variance and realized cross-sectional return variance and lagged realized cross-sectional return variance is 0.38 and 0.14 , respectively. This result implies that the covariance between past-realized cross-sectional return variance and option-implied crosssectional variance leads to the outcome where the parameter estimate of the lagged realized cross-sectional return variance becomes significant in the model of Equation (18). Another interesting issue evident from Table VI is that even option-implied cross-sectional return variance is at least marginally significant when employing this bootstrapping procedure. Together these robustness checks provide strong support for our previous results.

\section{CONCLUSION}

Recent research has established links between a range of asset pricing anomalies and crosssectional RD in both equity and currency markets. Chichernea et al. (2015), Pastor and Veronesi (2009), and Demirer and Jategaonkar (2013) argue that cross-sectional RD is a macroeconomic state variable. Changes in the state of the aggregate economy are not only of fundamental importance to investors but to policy makers too.

Much of the research to date has studied either implied volatility as a predictor of future realized volatility or implied correlation as a predictor of future realized correlation. This is the first paper to make use of both measures and investigate whether implied cross-sectional return variance has predictive power for forecasting future cross-sectional return variance. We use the concept of cross-sectional RD in a currency market setting, and employ the more convenient implied cross-sectional return variance as a straightforward measure of dispersion. In doing so, we compound four different measures for implied cross-sectional return variance, depending on the option-price maturity.

Our findings indicate that implied cross-sectional return variance based on 1 - and 3month maturity has predictive power beyond that of past-realized cross-sectional return variance. In fact, we find that implied cross-sectional return variance based on 1- or 3-month maturity are efficient predictors, whereas the implied measure based on the 1-month maturity yields the highest explanatory power in terms of $R$-squared values. Future research might target extending the current research to equity market indices where the implied correlation structure is obtainable. Another interesting avenue for future research would be to incorporate our findings in implementing trading rules in real time. For instance, employing the contemporaneous cross-sectional currency RD, Grobys et al. (2015) show that changes in cross-sectional currency RD partially explain momentum payoff in the FX market. The average payoff differential between states of high and low cross-sectional currency RD is $1 \%$ per month. Although our proposed option-implied measure of cross-sectional currency $\mathrm{RD}$ provides a 1-month to 3-month ahead forecast, it would be an interesting topic for future research to explore whether implied cross-sectional currency RD could be used to implement a real time trading strategy to exploit the payoff differential in momentum strategies in different states of cross-sectional currency RD.

\section{REFERENCES}

Blair, B., Poon, S.-H., \& Taylor, S. (2001). Forecasting S\&P100 volatility: The incremental information content of implied volatility and high frequency index returns. Journal of Econometrics, 105, 5-26.

Bodurtha, J. N., \& Shen, Q. (1999). Historical and implied measures of value at risḱ: The DM and Yen case. Working paper, Georgetown University, Washington, D.C.

Busch, T., Christensen, B. J., \& Nielsen, M. (2011). The role of implied volatility in forecasting future realized volatility and jumps in foreign exchange, stock, and bond markets. Journal of Econometrics, 160, 48-57. 
Campa, J. M., \& Chang, K. (1998). The forecasting ability of correlations implied in foreign exchange options. Journal of International Money and Finance, 17, 885-880.

Canina, L., \& Figlewski, S. (1993). The informational content of implied volatility. Review of Financial Studies, 6, 659-681.

Chang, B.-Y., Christoffersen, P., Jacobs, K., \& Vainberg, G. (2011). Option-implied measures of equity risk. Review of Finance, 15, 1-44.

Chichernea, D. C., Holder, A. D., \& Petkevich, A. (2015). Does return dispersion explain the accrual and investment anomalies? Journal of Accounting and Economics, 60, 133-148.

Christensen, B., \& Prabhala, N. (1998). The relation between implied and realized volatility. Journal of Financial Economics, 50, 125-150.

Day, T., \& Lewis, C. (1992). Stock market volatility and the information content of stock index options. Journal of Econometrics, 52, 267-287.

Della Corte, P., Ramadorai, T., \& Sarno, L. (2016). Volatility premia and exchange rate predictability. Journal of Financial Economics, 120, 21-40.

Della Corte, P., Sarno, L., \& Tsiakas, I. (2011). Spot and forward volatility in foreign exchange. Journal of Financial Economics, 100, 496-513.

Demirer, R., \& Jategaonkar, S. P. (2013). The conditional relation between dispersion and return. Review of Financial Economics, 22, 125-134.

Fleming, J. (1998). The quality of market volatility forecasts implied by S\&P100 index option prices. Journal of Empirical Finance, 5, 317-345.

Garman, M. B., \& Kohlhagen, S. W. (1983). Foreign currency, option values. Journal of International Money and Finance, 2, 231-237.

Godfrey, L. (2009). Bootstrap tests for regression models. London: Palgrave Texts in Econometrics.

Gomes, J., Kogan, L., \& Zhang, L. (2003). Equilibrium cross section of returns. Journal of Political Economy, 111 , 693-732.

Grobys, K. (2015). Is the asset growth anomaly driven by macroeconomic states? Applied Economics Letters, 23, $576-579$.

Grobys, K., \& Kolari, J.-W. (2015). Return dispersion and cross-sectional asset pricing anomalies. Proceedings of the 2015 Paris Financial Management Conference.

Grobys, K., Heinonen, J.-P., \& Kolari, J.-W. (2015). Is momentum in currency markets Driven by global economic risk? Proceedings of the 2015 Auckland Finance Meeting.

Higham, N. (2002). Computing the nearest correlation matrix-A problem from finance, IMA. Journal of Numerical Analysis, 22, 329-343.

Jiang, X. (2010). Return dispersion and expected returns. Financial Markets and Portfolio Management, 24, 107-135.

Lamoureux, G., \& Lastrapes, W. D. (1993). Forecasting stock-return variance: Toward an understanding of stochastic implied volatilities. Review of Financial Studies, 6, 293-326.

Lopez, J., \& Walter, C. (2000). Is implied correlation worth calculating? Evidence from foreign exchange options and historical data. Journal of Derivatives, 7, 65-82.

Maio, P. (2016). Cross-sectional return dispersion and the equity premium. Journal of Financial Markets, 29, 87-109.

Markowitz, H. M. (1952). Portfolio selection. Journal of Finance, 7, 77-91.

Menkhoff, L., Sarno, L., Schmeling, M., \& Schrimpf, A. (2012). Currency momentum strategies. Journal of Financial Economics, 106, 660-684.

Nikolaou, K., \& Sarno, L. (2006). New evidence on the forward unbiasedness hypothesis in the foreign exchange market. Journal of Futures Markets, 26, 627-656.

Pastor, L., \& Veronesi, P. (2009). Technological revolutions and stock prices. American Economic Review, 99, 1451-1483.

Siegel, A. F. (1997). International currency relationship information revealed by cross-option prices. Journal of Futures Markets, 17, 369-384.

Skintzi, V. D., \& Refenes, A.-P. N. (2005). Implied correlation index: A new measure of diversification. Journal of Future Markets, 25, 171-197.

Szakmarya, A., Orsb, E., Kimc, J.-K., \& Davidson, W.-N. (2003). The predictive power of implied volatility: Evidence from 35 futures markets. Journal of Banking and Finance, 27, 2151-2175.

Zhang, L. (2005). The value premium. Journal of Finance, 60, 67-103. 